\title{
CONTROLE DE SI, DOR E REPRESENTAÇÃO FEMININA ENTRE LUTADORES(AS) DE MIXED MARTIAL ARTS
}

\author{
Samuel Oliveira Thomazini \\ Licenciado em Educação Física pela Universidade Federal do Espírito Santo (CEFD/UFES). \\ Cláudia Emília Aguiar Moraes \\ Mestre em Educação (CED/UFSC) e membro do Laboratório de Estudos em Educação Física (LESEF).
}

\section{Felipe Quintão Almeida}

Mestre em Educação (CED/UFSC), doutorando em Educação (CED/UFSC) e membro do Laboratório de Estudos em Educação Física (LESEF) e do Núcleo de Estudos e Pesquisa Educação e Sociedade Contemporânea (CED/UFSC).

\begin{abstract}
Resumo
Esta é uma pesquisa realizada em três academias especializadas em Mixed Marcial Arts (MMA), em que se analisam alguns elementos indispensáveis à forja identitária de lutadores dessa modalidade. A etnografia durou sete meses, oportunidade para combinar uma observação participante, devidamente registrada no diário de notas, com a realização de entrevistas semi-estruturadas com atletas. Fotografias e filmagens dos locais de treinamento e de competição foram recursos metodológicos também úteis. Os resultados indicam a existência de processos bioidentitários vinculados ao controle de si e à racionalização da dor, apontando, além disso, para uma representação ambígua da presença feminina em um universo ainda predominantemente masculino.

Palavras-chave: esporte de combate - educação do corpo - identidade
\end{abstract}

\section{Introdução}

$\mathrm{D}$ esde o seminal estudo de Wacquant (2002), inúmeros trabalhos de cunho etnográfico foram produzidos nas academias e/ou clubes que oferecem esportes de combate e/ou artes marciais. Este estudo se insere neste movimento ao realizar uma pesquisa, também etnográfica, em academias especializadas na prática de Mixed Marcial Arts (MMA), termo que corresponde à denominação mais recente da prática corporal que mundialmente ficou conhecida como ValeTudo, esporte caracterizado pelo emprego de técnicas corporais oriundas de diversas artes marciais e/ou esportes de combate, ${ }^{1}$ tais como

1 Para maiores informações sobre a presença e desenvolvimento do MMA no Brasil, sugerimos consultar o pioneiro trabalho de Nunes (2004), com atletas homens de MMA na cidade de Porto Alegre. o jiu-jitsu, o boxe, o kickboxer, o muai thay, a luta greco-romana, o kung fu, e outros. Nossa presença no campo teve o objetivo geral de entender os processos concernentes à forja identitária do lutador de MMA, seja este homem ou mulher.

O trabalho de campo foi realizado em três academias, na cidade de Vila Velha (ES). Nos sete meses imersos no campo, entre novembro de 2007 e junho de 2008, combinamos a observação participante, devidamente registrada no diário de notas, com a realização de entrevistas semi-estruturadas com sete atletas de MMA (seis homens e uma mulher), dois treinadores especializados em MMA e uma atleta de boxe, que era sparring ${ }^{2}$ da supracita-

2 O sparring representa tanto um(a) lutador(a) quanto uma dinâmica de treinamento. Um(a) lutador(a) é um sparring quando participa de um treinamento (luta no ringue) com outro(a) lutador(a) (geralmente superior tecnicamente) e tem seu valor mediante o grau de dificuldade que ele(a) pode impor a seu oponente, no sentido de proporcionar-lhe com 
da lutadora de MMA. Nessas entrevistas, procuramos valorizar desde a vinculação inicial dessas pessoas com "o mundo" das artes marciais e/ou esportes de combate (suas histórias de vida), até chegar ao seu envolvimento com treinos e competições, visando esta modalidade específica. Fotografias e filmagens dos locais de treino e também das competições que os(as) lutadores(as) das academias participaram foram um recurso metodológico importante. A aproximação e inserção nestes campos foi favorecida pelo fato de um dos observadores ter exercido, durante anos, o ofício de lutador e professor de kickboxer naquela cidade, sendo previamente conhecido da maioria dos sujeitos que participaram desta investigação.

Neste artigo, divulgamos um recorte da etnografia realizada, de modo a descrever, inicialmente, dois aspectos importantes à forja identitária dos(as) atletas em questão: (1) a incorporação de um ethos esportivo baseado no controle de si e na distinção entre o ringue e a rua e (2) a valorização de um ethos sacrificial vinculado à racionalização da dor e do sofrimento corporal. Discutimos também (3) as representações que a presença feminina suscitava entre os atletas e as táticas das atletas de nosso campo para adquirir visibilidade e legitimidade naqueleuniverso predominante masculino. A estratégia básica, nos três tópicos, foi cotejar os elementos da pesquisa realizada com a literatura existente a respeito. Reservamos as considerações finais para um sucinto balanço dos elementos apresentados.

maior intensidade as duras provações que um(a) lutador(a) deve "passar" antes do "grande dia" (da luta propriamente dita). Assim, uma "luta" (treinamento) com estas características, também é chamada de sparring.

\section{Entre a rua e o ringue:}

o controle de si ou o ethos do lutador

Wacquant (2002), em seu célebre estudo com lutadores de boxe, conclui que o espaço da academia constitui uma verdadeira escola da moralidade, uma máquina capaz de fabricar o espírito da disciplina e do sacrifício que converge para o controle e a domesticação da força física e da violência desmedida contra o outro. Esse domínio de si (do seu corpo) é o que determina e justifica, sob um código de conduta rígido e diferenciado, o habitus pugilístico. Nessas circunstâncias, é considerado imoral todo aquele comportamento que contraria o ethos do grupo a que pertence o praticante. Em nosso trabalho no campo, os gladiadores entrevistados, para lembrarmos da representação que os(as) lutadores(as) gostavam de se vincular, foram unânimes em afirmar que nada mais se contrapõe ao ethos em que são socializados do que o uso de suas técnicas fora do único espaço em que elas deveriam ser empregradas: $\mathrm{o}$ ringue. Há uma distinção muito marcante entre o que é uma luta de MMA (portanto, legítima e moral) e o que é considerado briga. A trocação $0^{3}$ dentro de um ringue, seja a praticada com o companheiro/companheira de sparring, seja a que acontece no combate em uma competição, é o motivo que leva todo atleta de MMA à vida de privação e de sacrifício (dentro e fora do ringue), sem a qual jamais tornar-se-ia um(a) guerreiro(a), outra representação que os lutadores/lutadora gostavam de empregrar para referir a si próprios. O que escapa a este propósito, como as brigas de rua, significa entre eles um comportamento totalmente contrário à forja de um "lutador de verdade". Dois agentes do campo assim se manifestam a respeito: "Luta

3 Termo utilizado pelos lutadores/lutadora para referir-se à luta efetuada "em pé", em que os(as) atletas usam socos, chutes, joelhadas e cotoveladas, não sendo permitidas quedas e luta no chão. 
é dentro do ringue. $\mathrm{Na}$ rua é briga, é coisa de moleque, de marginal" (lutador D). "Só existe luta no ringue. $\mathrm{Na}$ academia é treino e na rua é tumulto, confusão, agressão física" (lutador C). A mesma opinião prevalece entre os investigados quando se discute a realização dos eventos clandestinos de MMA, pois estes apenas contribuem para denegrir a imagem do esporte: "[...] os caras lutando como se fossem animais, não é essa visão que a gente quer no esporte; o vale tudo não é briga de animais, é um esporte, um esporte que tem regras; agora é o MMA, não é vale tudo, acho que esses caras tinham que estar tudo na cadeia” (Lutador B); “[...] sou contra as lutas clandestinas. Acho que é uma desvalorização do atleta que está ali, compete; não dá segurança, não tem ambulância, não tem estrutura; aqui no Brasil virou uma febre, qualquer academia está fazendo luta e acha bonito esse tipo de coisa" (Lutadora).

Os relatos acima são semelhantes aos presentes em Wacquant (1998), pois seus entrevistados afirmavam evitar as brigas de rua não tanto devido às complicações legais que isso poderia provocar, mas porque esse comportamento violaria sua ética profissional. Estabelecem, assim, “[...] uma demarcação aguda entre boxe e briga de rua, e insistem em que suas habilidades profissionais ('é uma coisa do tipo técnico') não devem ser confundidas com briga de rua" (WACQUANT, 1998, p. 77). Constatação idêntica obtemos no trabalho de Nunes (2004), pois também em sua pesquisa de campo, dessa vez com atletas de MMA (todos homens), os brigões são mal vistos pois seu comportamento dificulta não somente a obtenção de recursos e patrocínios para os verdadeiros lutadores de MMA, mas também coloca inúmeras barreiras à legitimação e consolidação deste esporte no Brasil. Em relação a isso, assim se refere o lutador F:

[...] em vez de ajudar o esporte em si, isso atrapalha, porque a sociedade já vê o esporte como meio de marginalidade e olhando com os olhos que a gente vê os caras lá quebrando tudo, batendo no vidro, quebrando a cabeça, sem um ringue. Colocando em outras palavras, é assim: saiu do ringue não é mais luta.

A literatura nacional tem empregado os termos "pit boy" e "casca grossa", respectivamente, para caracterizar aqueles indivíduos que não fazem o uso "correto" das técnicas de luta que dominam (imorais, se considerarmos o ethos que deveriam respeitar e reproduzir) e aqueles que fazem o uso conforme determina o código de conduta do esporte em questão. Nas palavras de Ceccheto (2004, p. 170), essa classificação “[...] expressa a tendência ao caráter positivo que a violência ganhou entre esses grupos (os pit boys), e a segunda refere-se ao lutador experiente, ícone da superioridade técnica e de compromisso com a ética competitiva baseada em regras". A figura do "casca grossa" corresponde àquele lutador que, identificando no seu corpo o instrumento de trabalho e uma arma poderosa (WACQUANT, 1998), entende que o uso das habilidades de seu corpo-arma fora dos espaços (permitidos) tornar-se-á contraditório à ética do bom lutador ou lutadora: "Uma luta no ringue são dois atletas profissionais, treinaram para fazer aquilo ali. Uma luta na rua você pode pegar um cara que nunca fez nada, e simplesmente é uma covardia você bater num cara na rua que nunca fez nada; é uma arma: é você armado e o cara desarmado" (Lutador A). Aqui vale o mesmo que Diógenes (2003) e Ceccheto (2004) concluíram em relação aos lutadores de jiu-jitsu: os lutadores de MMA também disciplinam e controlam, na labuta diária do treinamento, seus apetites vorazes. Realizam uma transformação em seus corpos, que de um mero corpo lugar-de-raiva, morada de agressões descontroladas, modifica-se em um corpo arma-branca, não explosivo. A dedicação religiosa aos treinos e a adesão ao ethos que envolve a prática do MMA, funcionaria, assim, como uma protocolar prática disciplinar 
capaz de se opor à violência sem razão dos confrontos imprevistos, sem limites e sem sentidos, tal como aqueles que muitas vezes vimos ser noticiados na imprensa brasileira durante o processo de popularização deste esporte no Brasil, a partir da década de 1990. Esse controle do próprio corpo, de sua força física ou da violência em potencial que ele encerra (presente e legítima nos ringues, mas imoral quando usada nas ruas), além de fazer parte do dispositivo geral de preservação do corpo do(a) lutador(a) de MMA, constitui peça fundamental à forja de sua identidade, da sua identificação com e no grupo.

Assim, "[...] a figura do professor ocupa um lugar importante na construção do 'estilo' de um lutador: ele pode concorrer, grosso modo, para disciplinar as paixões ou para estimular o comportamento deliberadamente agressivo dos lutadores" (CECCHETO, 2004 , p. 151). Isso está também muito presente nas falas dos dois treinadores entrevistados: "Em relação às brigas, tem professor que se promove com isso [cita vários nomes]. Mas o fim dessa rapaziada é morte, cadeia ou aceitar Jesus. [...] Isto tudo é verdade! Não tenho raiva dos meninos não! Mas são atletas queimados [...]" (Treinador Y).

\begin{abstract}
Eu sou totalmente contra as brigas, sempre tem uns que gostam das brigas. Eu tenho um projeto social e tento conscientizar os moleques. Mas eu digo uma coisa: não é pra levar desaforo pra casa. Se for para se defender... Na conversa tudo se resolve. Parece que os caras (alunos) se espelham no professor; se o cara é brigão (o professor), parece que os caras procuram. $\mathrm{E}$ o que mais tem é professor que estimula isso. $\mathrm{O}$ vale tudo foi um fator positivo na diminuição da violência, ou seja, o brigão na rua não vai ser chamado pra eventos (Treinador $\mathrm{X}$ ).
\end{abstract}

“O professor é que 'faz' o aluno, isto é, o perfil do lutador seria debitado à orientação dada pelo treinador" (CECCHETO, 2004, p. 151). Assim concebido, o(a) mestre é mais do que um(a) instrutor(a) técnico(a), sendo reconhecido não apenas por seu capital de compe- tência na prática do esporte em questão, mas também por exercer uma influência moral e uma autoridade na relação que mantém com seus alunos. Desse modo, se as academias constituem escolas da moralidade, como diz Wacquant (2002), os(as) mestres(as) são seus/ suas professores(as).

\section{O convívio ou a racionalização da dor: no pain, no gain!}

Se a coragem, a ousadia, a valentia e a técnica apurada são pré-requisitos para se tornar um(a) lutador(a) "casca grossa", o caminho percorrido para alcançar tal status deve ser trilhado "sobrevivendo-se" a um treinamento que impõe, entre outras regras já constituídas pelo grupo, a convivência diária e constante da dor. Suportar as intermináveis dores em partes diferentes do corpo, sem ser persuadido a desistir do seu propósito ou mesmo enfraquecer o espírito e o corpo guerreiro (NUNES, 2004), se torna uma "regra" de conduta, um modo de operar, possibilitando um reconhecimento coletivo capaz de transformá-lo em um(a) legítimo(a) representante desta casta, os homens de ferro (GASTALDO, 1995) (mulheres de ferro, porque não!). O reconhecimento da dor como elemento intrínseco à construção do corpo do(a) guerreiro(a) ou do(a) gladiador(a) é um pré-requisito comum não só aos lutadores/lutadora de nosso campo de trabalho, mas trata-se de um componente fundamental da forja de qualquer praticante de esporte de combate (WACQUANT, 1998, 2002; CECCHETO, 2004; GASTALDO, 1995; NUNES, 2004; TURELLI; VAZ, 2006) ou esporte de caráter mais viril, como o rúgbi (RIAL, 1998). ${ }^{4}$ Ela parece ser, como

\footnotetext{
4 O domínio da dor (do corpo, portanto) não é exclusividade dos esportes de caráter mais viril, mas encontra-se também presente nas modalidades em que não há qualquer contato físico, como o atletismo, o balé e mesmo as atividades de treinamento corporal que acontecem em academias de ginástica e musculação. Conferir, a este respeito, Gonçalves (2007), Torri, Bassani e Vaz (2007) e Hansen e Vaz (2004).
} 
Wacquant (1998) aponta, uma companheira inseparável daqueles que praticam estes esportes: "Os pugilistas devem também aprender a controlar e a conviver com o desconforto físico, com a dor e com os ferimentos" (WACQUANT, 1998, p. 84). Nas palavras do lutador B, "Isso aí a gente tem que aprender a conviver. $\mathrm{O}$ bom é você saber porque você está sentindo dor". Para o lutador A:

Geralmente o atleta está com alguma coisa doendo, ou o joelho, a coxa, a canela, mão, dedo, sempre tem alguma coisa, você nunca treina $100 \%$, não tem jeito. É um esporte de contato, de impacto, não tem como você não estar com um tostãozinho, uma torçãozinha no dedo, ou no cotovelo, uma bursite, alguma coisa está doendo, não tem jeito cara. A gente vai se virando: está doendo ali, força mais com a outra, está doendo a perna, chuta mais com a outra e protege a que está doendo e vai embora.

Muito embora os autores com os quais trabalhamos associem este aprendizado como medida simbólica da masculinidade dos lutadores, trata-se de um requisito que é comum também ao universo da lutadora de MMA que entrevistamos: "Dor é o tempo inteiro, é um chutando sua perna, sua cabeça e machuca a articulação, ameniza com gelo e às vezes com antiinflamatório. Temos um fisioterapeuta na nossa equipe que nos ajuda nisso" (Lutadora).

Como afirmam Turelli e Vaz (2006, p. 6), desenvolve-se nos espaços em que se praticam artes marciais e/ou esportes de combate, independente do sexo, uma poderosa pedagogia da dor e do sofrimento, que "[...] não é apenas aceita, mas considerada autêntica, com processos que a legitimam e com implicações para a educação do corpo. A dor em si é algo frente ao qual se deve ser indiferente, algo com o que se deve saber conviver". Antes de ser entendida como uma expressão irrenunciável da corporalidade, ela passa a representar um obstáculo a ser suportado, superado, ou, inclusive, tornado fonte de prazer (VAZ, 2001; RIAL, 1998).
Nas academias de MMA investigadas, está em jogo uma educação do corpo em que o trabalho pedagógico que ali acontece tem por função substituir um corpo não acostumado com pancadas por um corpo estruturado e fisicamente remodelado conforme as exigências da prática em questão. Sendo assim, os(as) lutadores(as) criam estratégias para sublimar a dor e suportar o sofrimento. Por um lado, procuram mitigá-la através do uso de medicamentos diversos, analgésicos, sprays, pomadas, ataduras, bolsas térmicas, equipamentos de proteção, enfim, uma série de artimanhas cujo propósito não é cessar a fonte da dor, mas permitir que o treinamento continue, mesmo com ela: "Claro, todo atleta sente em locais específicos. Tomo antiinflamatório, infelizmente uma automedicação, não tem como ficar indo no médico toda a semana por causa de uma dor, aí a gente usa uma pomada analgésica, um antiinflamatório, gelo" (Lutador E).

Por outro lado, conforme já haviam observado Nunes (2004) e Gastaldo (1995), os(as) atletas empregam técnicas que objetivam o fortalecimento das regiões mais atingidas, como a aplicação de golpes no colega de treino com o intuito de ele os assimilar melhor, até o momento de o corpo tornar-se indiferente ou resistente às investidas do(a) parceiro(a) de treino. Não surpreende que, na avaliação da lutadora de MMA, "Lutar na academia é um vale tudo todos os dias porque você se quebra treinando; acho que o treinamento é a parte mais difícil da competição; você conseguir agüentar aqueles dias de treinamento, tomando pancada, tomando bronca do treinador" (Lutadora).

No universo investigado, o treinamento sparring aparece como o exercício mais "vivo" desse aprendizado e convívio com a dor, na medida em que se o vivencia, várias e várias vezes, antes da luta propriamente dita. Como pudemos notar, os treinos sparring podem se tornar tão intensos, desafiadores e penosos que, perto deles, a luta parece mais fácil. De acordo com um de nossos informantes: 
O sparring que a gente faz, é o que eu ia falar, nosso treinamento é muito mais difícil que a luta. A luta em si o máximo que ela vai durar é quinze minutos, um treino dura em média duas horas, você faz cinco ou seis sparrings como se fosse a luta em si; então o treino é muito pior em si, porque é como se estivesse lutando, só que com várias pessoas (Lutador A).

Nessas circunstâncias, o sparring não prepara o corpo para o pior (que está por vir). Ele é o pior! O resultado é que, além de preparar o corpo do(a) guerreiro(a) para o combate, ele minimiza os possíveis danos que o(a) atleta pode sofrer devido às investidas do(a) adversário(a). Embora aos olhos do espectador neófito isso possa parecer uma vã brutalidade irracional ou uma orgia selvagem, constitui o efeito de um plano racional, composto de táticas e estratégias que, mesmo sendo muito violentas e dolorosas, nem por isso deixam de ser muito controladas e metódicas. Após assistirmos ao vídeo de um dos sparrings filmados, ficamos impressionados com a cooperação antagônica e/ou cláusulas não-contratuais que unia os dois lutadores naquela sessão meticulosa de treino: o lutador sabia em que local bater, com qual intensidade, quando devia recuar, se afastar, deixar o companheiro respirar um pouco, em suma, é dotado de um senso prático, corporal, mimético, que o coloca em condições de alcançar uma justa medida entre o leve e o pesado, em condições de garantir um treinamento duro mas sem grandes consequências à integridade física do seu colega de treino.

Essa aprendizagem radical da dor que acontece no sparring serve ainda para fomentar, entre os(as) lutadores(as), um domínio das emoções desencadeadas pelas trocas de socos e pontapés, bastante intensas em um combate de campeonato. Este trabalho emocional, associado à racionalização da dor física, é mais um poderoso elemento da constituição identitária do(a) lutador(a) de MMA (WACQUANT, 2002).

\section{Mulher no ringue:}

o que eles acham, o que elas pensam?

Estudos demonstram que o ambiente das academias de esportes de combate e/ou artes marciais é dominado por uma cultura masculina, permeada, no dizer de Gastaldo (1995), por uma semântica da virilidade que considera a presença feminina uma afronta à ordenação simbólica daquele universo. Em nossa pesquisa, a dissonância cognitiva encarnada nas mulheres também esteve presente. Ela manifestou-se na representação, conforme Ceccheto (2004) já havia observado, segundo a qual as mulheres têm uma tendência para a fraqueza e para a pouca resistência, o que dificulta o envolvimento delas em uma prática na qual se exige muita força e resistência. $\mathrm{O}$ lutador $\mathrm{C}$ assim se manifesta a respeito:

Para ser sincero acho ridículo. [...] acho que o MMA não está envolvido diretamente com mulheres. $\mathrm{O}$ esporte para a mulher seria o judô, o jiu-jitsu, o taekonwdo; acho que a mulher não tem essa agressividade que o homem tem a ponto de disputar o MMA, então não acho certo ou tão eficaz a mulher praticar o MMA.

O depoimento anterior revela não somente uma posição tipicamente de gênero (o esporte como produtor de corpos generificados), em que as mulheres são autorizadas a praticar os esportes mais adequados à sua "essência" - então incompatível com a ética do sacrificio (WACQUANT, 2002) imanente à preparação de um lutador desta modalidade -, mas também evidencia que a noção de agressividade ou virilidade está associada à masculinidade. Ao defender seu cargo de lutador contra a feminilização é a idéia mais "profunda" de si mesmo como homem que ele está pretendendo proteger, afinal, a cultura em que está inserido associa quase a totalidade de seu valor como lutador, perante a si próprio e aos demais, graças à imagem da virilidade. A presença feminina parece embaralhar essa representação. Soma-se a essa 
representação o fato de que, no mercado de bens simbólicos dominado pela visão masculina (BOURDIEU, 2007), como é o caso dos esportes de combate, a mulher é sempre vista pelo olhar do dominante, o lutador, que a avalia pelas características que ele tem e ela não. $\mathrm{Na}$ medida em que a mulher conquista tais características, e os valores a elas associados, $\mathrm{o}$ fundamento do discurso masculino torna-se (ainda mais) insustentável.

Um grupo de lutadores, sem perder de vista esta representação negativa relaciona$\mathrm{da}$ à presença feminina entre os praticantes de MMA, chega mesmo a delimitar "seus lugares" neste espaço. Por um lado, sua presença é legítima quando desfila sua beleza e suas formas nos intervalos entre os rounds de um combate, distraindo o público e os próprios lutadores (Lutador C); por outro lado, sua permanência é tolerada quando assumem uma postura de subordinação em relação aos atletas. As "Marias-tatames" são um exemplo desse caso, pois sua representação entre os lutadores corresponde à "[...] percepção da mulher como inelutavelmente interessada nas vantagens proporcionadas pelo lutador, ou melhor, pelo seu corpo, para protegê-la ou sustentá-la” (CECCHETO, 2004, p. 171). Afinal de contas, "Qual mulher que não gosta de ver um cara saradão ali de guerreiro; tem mulher que não gosta não, mas a maioria gosta. Mulher gosta de Homem né bicho, pegada forte" (Lutador D).

\begin{abstract}
Tem muita mulher que gosta de lutador, não vou dizer que são todas, mas te digo que não sei se é pela sensação de segurança que o lutador do lado pode passar, ou até mesmo pelo porte físico, ou até mesmo por está ali no meio da galera, aquela coisa toda, enfim, é fato que atrai, sendo "Maria-tatame" ou não (Lutador E).
\end{abstract}

A despeito desses constrangimentos normativos sobre a presença da mulher no esporte, conseguimos identificar nas academias investigadas representações masculinas que conseguem romper com aquelas hierarquias de gênero predominantes, a ponto de alguns lutadores verem com "naturalidade" a presença feminina nos ringues de MMA: "Eu acho bacana, eu admiro muito, não é fácil não, não só com o preconceito que é muito grande, mas é que elas treinam com homens porque não têm mulheres para treinar, a não ser isoladamente em outras artes [marciais]" (Lutador F); "Eu vejo como qualquer outro atleta. Minha irmã, por exemplo, eu vejo como qualquer outro atleta meu; não tem diferença entre homem e mulher; é como qualquer outro esporte" (Lutador A).

O depoimento de um dos treinadores chega mesmo a apontar para o caráter contingente das representações de gênero: "O esporte é pra todos, desde que lutem mulheres com mulheres e homens com homens. Existem mulheres bastante agressivas e homens sem nenhuma agressividade" (Treinador Y). Essa igualdade discursada entre os gêneros era notável, sobretudo, naqueles momentos de sparring em que o lutador A e a lutadora se enfrentavam no ringue. A trocação era realmente bastante intensa entre eles, pouco importando ao lutador se do outro lado estava uma mulher, que ainda por cima era sua irmã biológica. $\mathrm{O}$ fato de a lutadora encarar o momento mais árduo de toda a preparação (o sparring) enfrentando um homem minimiza as diferenças socialmente construídas entre os sexos, estremecendo, assim, o mito da fragilidade feminina. Para nós, espectadores daquela situação, quando a lutadora estava no sparring com um homem, mais do que sua beleza e curvas, os atributos destacados eram sua força, coragem, ousadia, garra e seu destemor em lutar com outro homem (maior e mais pesado), todas essas qualidades que seriam postas à prova no combate com outra guerreira, durante um campeonato. As iniciativas como a da lutadora de MMA contribuem para se definir novas formas de ser mulher, dando visibilidade, como disse Aldeman (2003), a outras representações da feminilidade. Nos dizeres da própria lutadora: 
Mulher tem aquela mania: ah, não vou lutar não porque sou frágil; eu acho que as pessoas vêem a luta para a mulher dessa forma $\mathrm{e}$ não é assim. A mulherada se acha delicada demais, muito fresca para treinar; a luta tem a característica de ser grosseira e a mulher tem a característica de ser o sexo frágil; não é assim, a gente é batalhadora e guerreira como os homens (Lutadora).

No caso da lutadora de boxe, essa reinvenção da feminilidade e da própria fisicalidade (DEVIDE, 2005) passa pela necessidade de ela ser mais durona, pois, segundo suas próprias palavras:

Eu ainda me sinto um pouco com o coração
mais aberto, então tô tentando cada vez mais
endurecer meu coração, não ter mais peninha
das oponentes; agora é mandar porrada e cair
dentro, senão é a gente que toma. [...] Porque
você não pode ter pena da pessoa, ela não vai ter
de você, então tem que ser pior que ela, meter
a porrada logo pra ela desmaiar, senão vou per-
mitir ela fazer isso comigo. Sangue azul é san-
gue frio é a mesma coisa de coração de pedra.

Essas mulheres forçudas (GOELLNER; FRAGA, 2003) do século XXI desnaturalizam, em suas práticas, as diferenças sexuais e, por conseqüência, de inferiorização feminina neste espaço "naturalmente" concebido como masculino. Fazem isso sem precisar assumir posturas masculinizantes, ${ }^{5}$ normalmente associadas àquelas que se "aventuram" em espaços tradicionalmente vistos como não apropriados para elas.

\section{Palavras finais}

Analisamos, neste artigo, alguns elementos que se mostraram relevantes à for-

5 A lutadora de boxe, por exemplo, tem clareza que a agressividade necessária à luta está restrita ao ringue e somente a ele. Já a lutadora de MMA gosta de destacar "sua feminilidade", lutando com luvas rosas, maquiada e de mariachiquinha nos cabelos, além de, ao final de cada vitória nos ringues, mostrar toda sua sensualidade com uma "sambadinha”, em suas próprias palavras. mação identitária dos lutadores e lutadora de MMA. Apresentamos o duplo ethos que os(as) atletas precisam assimilar para serem reconhecidos(as), entre seus iguais, como guerreiros(as) e "verdadeiros(as)" lutadores(as). Uma característica importante desse duplo ethos é que ele "atravessa", por assim dizer, os corpos dos(as) atletas, seja porque exige deles(as) um domínio de si cujo resultado é a transformação de seus corpos potencialmente explosivos em armas-brancas (pautado pela moral segundo a qual a briga fora dos ringues é coisa de marginal), seja porque implica em uma introversão do sacrifício que é naturalizada graças ao desenvolvimento de uma pedagogia baseada no controle e na racionalização da dor. Esse duplo ethos, ao ser assumido também pelas mulheres, desmitifica a idéia de que elas têm uma "essência" ou identidade que é incompatível com a prática dos esportes que envolvem um contato corporal mais acentuado, como é o caso dos esportes de combate.

E por falar em mulheres, a investigação identificou a existência de uma representação ambígua associada à presença feminina nas academias investigadas: ao mesmo tempo em que as academias são espaços de afirmação dos ideais predominantes de masculinidade, em que as mulheres ou são estigmatizadas como existências estranhas naquele universo ou como presenças submissas aos homens, alguns lutadores consideram a presença do sexo (não tão) "frágil" entre os ringues uma conquista que deveria ser respeitada e valorizada, sem que elas precisem ser assimiladas ao igual, perdendo, assim, sua própria alteridade. Essa representação, aliada às estratégias e táticas empregadas pelas mulheres na batalha diária do treinamento, é um importante passo na direção de romper, nos esporte de combate, com aquilo que Goellner (2006) denomina de estética da contenção: "[...] nada de excessos, nem de gorduras, nem de músculo, nem de ousadias, nem de inserções em espaços que parecem não ser seus". As meninas de nosso 
campo são excelentes exemplos de que, além de belas, as mulheres podem também ser literalmente fatais.

Self-control, pain and female representation among mixed martial arts fighters

\begin{abstract}
This research work was conducted in three gyms which specialize in Mixed Martial Arts (MMA). We analyzed elements which are essential to the forging of fighter identity in this type of fight. Ethnographic studies lasted for seven months, which gave us the opportunity to apply both participant observation - recorded in a field journal - and semi-structured interviews to the athletes. Photographs and video-recording of training and competition places were also carried out. Results indicate the existence of bioidentity processes linked to self-control and to the rationalization of pain, which point to an ambiguous representation of the presence of females in a still male-dominant environment.

Keywords: combat sports - education of the body identity
\end{abstract}

\section{Control de si mismo, dolor y presencia femenina entre luchadores(a) de mixed martial arts}

\section{Resumen}

La investigación fue realizada en tres gimnasios especializados en Mixed Marcial Arts (MAA), se analizaron rasgos esenciales de la construcción de las identidades de luchadores y luchadoras de esa modalidad. La etnografía duró siete meses, oportunidad para acordar una observación participante, registradas en el diario de notas, con la realización de entrevistas semi-dirigidas con atletas. Fotos y filmaciones de los locales de capacitación y de competencias también fueron recursos metodológicos útiles. Los resultados sugieren la presencia de procesos bioidentitarios vinculados al control de si y a la racionalización del dolor, y además, señalando hacia una representación ambigua sobre la presencia femenina en un universo donde predomina el masculino.

Palabras-clave: deporte de combate - educación del cuerpo - identidad

\section{Referências}

BOURDIEU, P. A dominação masculina. Rio de Janeiro: Bertrand Brasil, 2007.

CECCHETO, F. R. Violência e estilos de masculinidade. Rio de Janeiro: FGV, 2004.
DEVIDE, F. P. Gênero e mulheres no esporte: história das mulheres nos jogos olímpicos modernos. Ijuí: Unijuí, 2005.

DIÓGENES, G. Itinerários de corpos juvenis: o tatame, o jogo e o baile. São Paulo: Annablume, 2003.

GASTALDO, E. L. Kickboxer - esportes de combate e identidade masculina. 1995. $185 \mathrm{f}$. Dissertação (Mestrado em Antropologia Social) - Programa de Pós-Graduação em Antropologia Social, Universidade Federal do Rio Grande do Sul, Porto Alegre, 1995.

GOELLNER, S. Entre o sexo, a beleza e a saúde: o esporte e a cultura fitness. Labrys: estudos feministas, n. 10, jul./dez. 2006. Disponível em: http://www.unb.br/ih/his/gefem/ labrys10/riogrande/silvana.htm. Acesso em: 15 maio 2008.

GOELLNER, S.; FRAGA, A. B. Antinoüs e Sandwina: encontros e desencontros na educação dos corpos brasileiros. Movimento, Porto Alegre, v. 9, n. 3, p. 59-82, set./dez. de 2003.

GONÇALVES, M. C. Corpos e subjetivações: o domínio de si e suas representações em atletas e bailarinas. 2007. 118 f. Dissertação (Mestrado em Educação) - Programa de Pós-Graduação em Educação, Universidade Federal de Santa Catarina, Florianópolis, 2007.

HANSEN, R.; VAZ, A. F. Treino, culto e embelezamento do corpo: um estudo em academias de ginástica e musculação. Revista Brasileira de Ciências do Esporte, Campinas, v. 26, n. 1, p. 135-152, set. 2004.

NUNES, C. R. F. Corpos na Arena - um olhar etnográfico sobre a prática das artes marciais combinadas. 2004. $251 \mathrm{f}$. Dissertação (Mestrado em Ciências do Movimento Humano) - Programa de Pós-Graduação em Ciências do Movimento Humano, Universidade Federal do Rio Grande do Sul, Porto Alegre, 2004. 
RIAL, C. S. M. Rúgbi e judô: esporte e masculinidade. In: PEDRO, M. J.; GROSSI, M. P. Masculino, feminino, plural: gênero na interdisciplinaridade. Florianópolis: Editora Mulheres, 1998. p. 229-258.

TORRI, G.; BASSANI, J. J.; VAZ, A. F. Dor e tecnificação no contemporâneo culto ao corpo. Pensar a Prática, Goiânia, v. 10, n. 2, p. 261-273, jul./dez. 2007.

TURELLI, F. C.; VAZ, A. F. Rituais, masculinidade e representações de dor em caratecas. In: SEMINÁRIO INTERNACIONAL FAZENDO GÊNERO, 7., 2006, Florianópolis. Anais... Florianópolis: Editora Mulheres, 2006. p. 1-14.

WACQUANT, L. Os três corpos do lutador profissional. In: LINS, D. (Org.). $A$ dominação masculina revisitada. Campinas: Papirus, 1998. p. 73-96.
Corpo e Alma: notas etnográficas de um aprendiz de boxe. Rio de Janeiro: Relume Dumará, 2002.

VAZ, A. F. Técnica, esporte, rendimento. Movimento, Porto Alegre, v. 7, n. 14, p. 87-99, 2001.

Recebido em: 29/10/2008

Revisado em: 16/11/2008

Aprovado em: 26/11/2008

\section{Endereço para correspondência}

samuel_thomazini@hotmail.com

cea_moraes@hotmail.com

fqalmeida@hotmail.com 